\title{
Dental Caries and the Influence of Associated Factors - A Cross-Sectional Study
}

\author{
Aliya Ehsan¹, Jawwad Iqbal Afridi², Hina Abid³ , Muhammad Yusuf ${ }^{4}$ \\ ${ }^{1,2}$ Department of Operative Dentistry, University College of Dentistry, The University of \\ Lahore, Lahore, Pakistan. ${ }^{3}$ Department of Operative Dentistry, King Edward Medical \\ University Lahore, Pakistan. ${ }^{4}$ Lahore Medical \& Dental College, Lahore, Pakistan.
}

\section{ABSTRACT}

\section{BACKGROUND}

The study was carried out to determine the prevalence of dental caries among urban and suburban population in Pakistan to assess the association of dental caries with oral hygiene status, socioeconomic status, and dental service availability.

\section{METHODS}

A total of 200 patients was enrolled in this cross-sectional study. Decayed, filled, and missing teeth (DMFT), oral hygiene status, socioeconomic status (SES), and presence / absence of dental care facility were recorded. A specially designed proforma was used to record the data regarding oral hygiene practices, dental treatment availability and socioeconomic background, for the study. The data obtained was statistically analysed using SPSS version 15 software. Chi-square test was applied for association between categorical variables. Analysis of variance (ANOVA) was done to test the difference in DMFT scores of various age groups. Student $t$ test was applied to test the difference in DMFT scores in both sexes.

\section{RESULTS}

Comparison of mean $\mathrm{D}, \mathrm{M}$ and $\mathrm{F}$ status revealed a high tendency towards decayed teeth. Mean DMFT score was found to be 4.41. Maximum DMFT was recorded among 50 years and above age group, followed closely (2.39) by 40 - 49 years. Increased caries prevalence was seen in people with poor oral hygiene and belonging to low socioeconomic status. Caries rate was also high in areas with lack of dental care facilities.

\section{CONCLUSIONS}

Oral hygiene practices, dietary habits, and access to dental care services played an important role in prevalence of dental caries. Socio-economic status has been found to play an important role in access to dental care facilities. From the current report, importance for public health was noted; the socioeconomic status, educational status of parents, and family structure, affect oral health in under-privileged communities. The prevalence of dental caries also plays an important role in oral hygiene procedures, eating patterns, and access to dental care services.

\section{KEY WORDS}

Dental Caries, SES, Oral Hygiene, Dental Care Facility, DMFT.
Corresponding Author: Dr. Aliya Ehsan,

Department of Operative Dentistry, University College of Dentistry, The University of Lahore, Lahore, Pakistan,

E-mail: aliya8@hotmail.com

DOI: $10.14260 / j e m d s / 2021 / 336$

How to Cite This Article:

Ehsan A, Afridi JI, Abid H, et al. Dental caries and the influence of associated factors - a cross-sectional study. J Evolution Med Dent Sci 2021;10(21):1616-1620, DOI: $10.14260 /$ jemds $/ 2021 / 336$

Submission 07-12-2020,

Peer Review 14-03-2021,

Acceptance 20-03-2021,

Published 24-05-2021.

Copyright (C) 2021 Aliya Ehsan et al. This is an open access article distributed under Creative Commons Attribution License [Attribution 4.0 International (CC BY 4.0)] 


\section{BACKGROUND}

The most prevalent oral disease, dental caries, reveals a striking difference in its spread all over the world. The global distribution of dental caries poses a varied picture. ${ }^{1}$ Due to the preventive measures taken, a decline in the incidence of dental caries and increase in gingival health care are evident in many developed countries.

Migration from rural areas and urbanisation in developing countries triggers a shift in lifestyles and dietary habits, which in turn affects oral health. The Pakistan scenario also indicates rise in prevalence relative to other developing countries. Many oral health studies have shown rising trends in the prevalence of dental caries among children and adults. ${ }^{2}$ Socioeconomic status, low parental education status, and parental behaviours have an effect on the development of children's oral health habits.

The incidence, severity, distribution and trend of dental caries have changed globally. ${ }^{3}$ Caries is seen as a disease of economically developed countries for much of the twentieth century, with low prevalence in developing countries. ${ }^{4}$

For this pattern, there are many interrelated explanations. In economically developing countries, high intake of refined carbohydrates resulted in the selective proliferation of cariogenic bacteria ${ }^{5}$ and the consequent increase in the prevalence of dental caries in these countries. In the 1980s, the prevalence of dental caries in most Western countries decreased gradually, although at the same time the prevalence of dental caries in less developed countries increased. ${ }^{6}$

Many studies have indicated the relationship between increased industrialisation, urbanisation, consumerism, consumption of processed carbohydrates and dental caries.3,4,7,8 This present study was carried out to assess the prevalence of dental caries among urban and suburban population and to know the association of dental caries with oral hygiene status, socioeconomic status and dental service availability.

\section{METHODS}

This cross-sectional study was carried out in the Department of Operative Dentistry, University College of Dentistry (UCD), Lahore. The duration of study was one year, from June 2019 to May 2020. About 200 patients were included. Non-probability purposive sampling technique was used. To circumvent interexaminer variability, all the patients were seen by a single examiner. The patients were examined by using mouth mirror, explorer and community periodontal index of treatment needs (CPITN) probe. The World Health Organization (WHO) oral health assessment form 5 (1997) was used for recording dentition status. A specially developed proforma was used to document all data on oral hygiene habits, socioeconomic history and availability of dental care. Questionnaire included calculation of Decay-Missing-Filled- Tooth index, oral hygiene status based on community periodontal index (CPI) scores and socioeconomic status.

\section{DMFT}

For measuring severity of caries DMFT index is used: "Decaymissing-filled-tooth". ${ }^{3}$ It is most universally employed index for measuring dental caries, this index is based on the fact that dental hard tissues are not self-healing, developed caries leave a scar of some kind, the tooth either remains decayed or is removed or filled if treated. ${ }^{3}$ This is the method of choice in the simple survey methodology for the World Health Organization and is applied to all teeth.

\section{Calculation of Index $x^{3}$ \\ Individual DMFT}

Total separately for each variable i.e. D, M and F, then total D + $\mathrm{M}+\mathrm{F}=\mathrm{DMFT}$

\section{Group Average}

Total D, M, F for each individual, dividing the total DMF by number of individuals in the group i.e. average DMFT $=$ total DMFT / total no. of subjects examined.

\section{Oral Hygiene Status}

The community periodontal index (CPI) 9,10 was created by the WHO for the measurement of oral hygiene status in order to provide country profiles on periodontal health status and to encourage countries to plan intervention programs to effectively track periodontal disease. In addition, the CPI data may be helpful in oral health surveillance at national and international levels. Although this index is the means of assessing the degree and severity of periodontal disease, ${ }^{11} \mathrm{CPI}$ scores have usually been used:

- $\quad$ Score $0=$ Healthy periodontal conditions;

- $\quad$ Score 1 = Gingival bleeding;

- $\quad$ Score 2 = Gingival bleeding and calculus;

- $\quad$ Score 3 = Shallow periodontal pockets ( 4 to $5 \mathrm{~mm}$ );

- $\quad$ Score 4 = Deep periodontal pockets $(6 \mathrm{~mm})$.

In adult populations, the most severe score or symptom of periodontal disease (CPI score 4) ranges from $10 \%$ to $15 \%$ globally, but CPI score 2 (gingival bleeding and calculus) is the most prevalent score in all regions, which mainly represents poor oral hygiene. ${ }^{9,10}$ Urbanisation indicates major variations in the prevalence of periodontal disease. The influence of socio-environmental factors was evident in the various profiles of periodontal diseases seen in people living in those populations. The community periodontal index had been used as follows: 12

- $\quad$ Good oral hygiene $=$ score 1

- $\quad$ Average oral hygiene $=$ score 2

- $\quad$ Poor oral hygiene $=$ score 3

\section{Socioeconomic Status (SES)}

Different methods are available to identify socioeconomic classes. One of them was the use of per capita gross national product (GNP) to form groups, in order to increase internal homogeneity. ${ }^{13}$

The analytical alternative was to use tests to assess the health effect or impact of socioeconomic status. Measures of impact are based on a fixed socio-economic component group (e.g., primary education versus university education). Measures of effect, in comparison, use categories identified by a socioeconomic indicator quantifiable in population terms (e.g., highest income quintile versus lowest income quintile), 
so that if the distribution of the indicator varies, the calculation of inequality also got modified. ${ }^{14}$

- Low SES - monthly earning of $<$ Rs. 6000

- High SES - monthly earning of $>$ Rs. 50,000

- Middle SES - monthly earning between Rs. 6000 - 50,000

\section{Statistical Analysis}

The data obtained were statistically analysed using SPSS version 15 software. Chi-square was used to test the association between categorical variables. ANOVA to test the difference in DMFT scores of various age groups, level of significance is considered 0.05 . Student $t$ test is applied to test the difference in DMFT scores in both sexes.

\section{RESULTS}

This cross-sectional study was done on 200 individuals comprising of $80(40 \%)$ males and $120(60 \%)$ females. Most of the respondents were in the age group of $20-29$ years, 79 individuals (39.5\%) and few were aged 50 years and above, $11(5.5 \%$ ) (Table 1). Majority of individuals seeking treatment were from poor socioeconomic background with 120 (60\%), followed by middle class 69 (34.5\%) and only 11 (5.5\%) were from upper class. Most of them had poor oral hygiene 105 (52.5\%), average oral hygiene in 76 (38\%) and good oral hygiene in 19 (9.5\%). Majority, 119 (59.5\%) of them had no access to dental health facilities whereas about 80 (40.5\%) had access to dental facilities. (Table 2)

\begin{tabular}{|cccccc|}
\hline Age of Patients & $\mathbf{N}(\%)$ & Mean & SD & f-Value & P-Value \\
$<$ < 20 years & $42(21 \%)$ & 2.0 & 0.297 & & \\
20 - 29 years & $79(39.5 \%)$ & 1.95 & 0.221 & & \\
30 - 39 years & $41(19.5 \%)$ & 1.95 & 0.120 & 1.732 & 0.14 \\
40 - 49 years & $27(13.5 \%)$ & 2.39 & 0.230 & & \\
50 years and above & $11(5.5 \%)$ & 2.95 & 0.110 & & \\
\hline \multicolumn{6}{c}{ Table 1. Age Wise Distribution of Patients. } \\
\hline
\end{tabular}

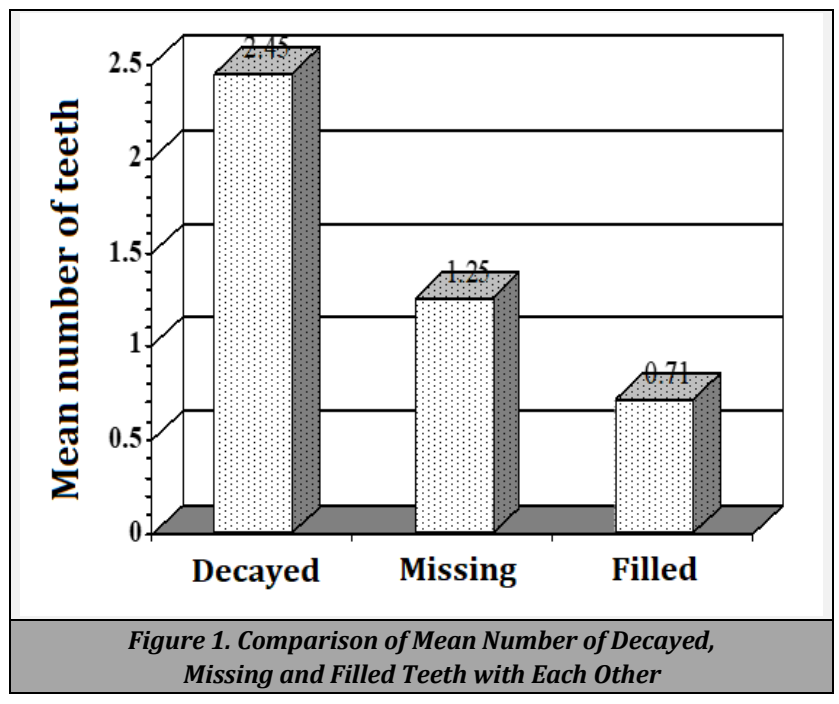

Comparison of mean D, M and F status revealed a high tendency towards decayed teeth 2.45 , while 1.25 were missing and only 0.71 were filled in the sample. Mean DMFT score was found to be 4.41. Mean DMFT was high (2.95) among 50 years and above age group, followed closely (2.39) by 40 - 49 years.
Patients less than 20 years of age had high DMFT (2.00). However, patients of 20 - 29 and 30 - 39 age group showed almost similar trend of (1.95) and (1.97) respectively. In females DMFT was found to be (1.97) as compared to males (1.95), it showed a trend towards slightly higher in females, as compared to males. High DMFT (1.98) was found in patients belonging to low SES. There was also raised trend (1.93) in patients with middle SES as compared to (1.91) of high SES. Results were statistically significant (P-value $<0.01$ ) in showing predominant DMFT (1.99) in people with poor oral hygiene as compared to average (1.97) and good oral hygiene (1.74). The absence of facilities denoted an increased DMFT (1.98) as compared to presence of facilities (1.93). The result was statistically significant (P-value 0.04).

\begin{tabular}{|c|c|c|c|c|c|c|}
\hline & $\begin{array}{c}\text { Sex of } \\
\text { Patient }\end{array}$ & N (\%) & Mean & SD & & \\
\hline \multirow{2}{*}{$\begin{array}{l}\text { Comparison of mean } \\
\text { DMFT score with respect } \\
\text { to gender }\end{array}$} & Male & 80 & & 9 & \multirow{2}{*}{$\begin{array}{c}\text { t-value } \\
0.344\end{array}$} & \multirow{2}{*}{$\begin{array}{c}\text { P-value } \\
0.56\end{array}$} \\
\hline & Fem & $120(60 \%)$ & 1.97 & 0.180 & & \\
\hline \multirow{3}{*}{$\begin{array}{l}\text { Comparison of mean } \\
\text { DMFT with respect to } \\
\text { socioeconomic status }\end{array}$} & High & $11(5.5 \%)$ & 1.91 & 0.302 & \multirow{3}{*}{$\begin{array}{c}\mathrm{f} \text { value } \\
2.184\end{array}$} & \multirow{3}{*}{$\begin{array}{c}\text { P value } \\
0.115\end{array}$} \\
\hline & Middle & $69(34.5 \%)$ & 1.93 & 0.261 & & \\
\hline & Low & $120(60 \%)$ & 1.98 & 0.129 & & \\
\hline \multirow{3}{*}{$\begin{array}{l}\text { Comparison of mean } \\
\text { DMFT with respect to } \\
\text { oral hygiene status }\end{array}$} & Good & 19 (9.5\%) & 1.74 & 0.452 & \multirow{3}{*}{$\begin{array}{l}\text { f value } \\
15.736\end{array}$} & \multirow{3}{*}{$\begin{array}{l}\text { P value } \\
<0.01\end{array}$} \\
\hline & Average & 76 (38 \%) & 1.97 & 0.161 & & \\
\hline & Poor & $\begin{array}{c}105(52.5 \\
\%)\end{array}$ & 1.99 & 0.098 & & \\
\hline \multirow{2}{*}{$\begin{array}{l}\text { Comparison of mean } \\
\text { DMFT with respect to } \\
\text { dental care facilities }\end{array}$} & Yes & $81(40.5 \%)$ & 1. & 0.264 & \multirow{2}{*}{$\begin{array}{c}\text { t value } \\
4.16\end{array}$} & \multirow[b]{2}{*}{$\begin{array}{l}\text { P value } \\
<0.01\end{array}$} \\
\hline & No & $\begin{array}{c}119(59.5 \\
\%) \\
\end{array}$ & 1.98 & 0.129 & & \\
\hline
\end{tabular}

\section{DISCUSSION}

In most developing countries, oral health has improved remarkably due to numerous rapid developments in the field of preventive dentistry. Oral diseases are on the rise in developed countries and in particular, in underprivileged communities. This may be due to inadequate access to dental services, technology and vocational training skills. This study attempted to identify the prevalence of caries and the possible relation between various factors that can affect the status of population caries.

The Pakistan Health Survey was conducted in 1991 - 94.16. The survey looked at adult dental health and only noticed decayed and missing teeth. The DM score for $15-24$ year olds was 2 according to that report, but this score increased to 21 in the age group of 65 years. 149 The available data on the prevalence of dental caries in Pakistan showed that Pakistan can be categorised as a country with low caries.

50 percent of children aged 12 - 15 years were caries-free, but 97 percent of all carious lesions were untreated on the negative side. ${ }^{15,16}$

The outcomes of this analysis were identical to the previous results published. With the mean DT score (2.45), decayed teeth were predominant, while the mean MT score for missing teeth was (1.25) and the MF score for the filled portion was (0.71). Negligence and complete absence of care were evident in all age groups, especially in the population aged 30 years and above. This finding also relates to the lack of dental care facilities, especially for individuals in low-income groups.

Comparison of mean DMFT with patient age revealed that the most influential group affected by caries with mean DMFT score was patients within the age range of 50 and above years 
(2.95). Another striking finding among patients aged 40 years and above was an improved mean DMFT score (2.39). This result is comparable to other studies ${ }^{17,18}$ in which adults aged 25 - 54 years have the greatest need for dental care. It's been anticipated that needs increase with population growth as the teeth are retained longer. The obstacles listed were the cost of care, the dentist's anxiety, immobility, and the feeling that the dentist should not be bothered by them.

Mean DMFT (1.97) was seen in patients between 30 - 39 years of age, a marginally low score relative to above age groups. All of these results are associated with the high score of decayed and missing teeth compared with filled teeth. 19,20,21 Patients less than 20 years of age showed a high mean DMFT score (2.00), while patients of 20 - 29 years age group showed mean DMFT score of (1.95), so generally in young patients DMFT score was found to be high.., 22

The recent most pathfinder survey was done in $2004 .^{23}$ According to this survey the DMFT scores for 12-year-old, 15year-old, 35 - 44-year-old and 65-year-old were 1.38, 1.94, 8.02 and 17.73 respectively. ${ }^{23}$ Our results were pretty same with high mean DMFT score in adults and elderly population as compared to young adults. ${ }^{24,23}$

Another interesting finding was that female group had higher level of caries with mean DMFT score (1.97) as compared to males (1.95). These results are consistent with the studies done in America and Europe ${ }^{20,21}$ but the studies done in India narrate that males have higher DMFT score. ${ }^{24,9}$ This difference has been attributed to the earlier eruption of teeth in females, ${ }^{25}$ but this explanation is hard to support when the differences are seen in older age groups. As mentioned earlier it's hard to say anything on this difference of results from the rest of the world, as more surveys and understanding of this disease pattern is required in our population.

In this study 200 patients were examined randomly. Results of this study showed $60 \%$ of the patient seeking treatment for dental caries belonged to lower class, while 34.5 $\%$ belonged to middle and only $5.5 \%$ belonged to upper class. This shows a high trend of caries towards lower socioeconomic status. ${ }^{26,27-29}$ The mean DMFT score in low socioeconomic group was (1.98), in middle SES it was (1.93), while in high socioeconomic status it was (1.91). People from low socioeconomic group had slightly high DMFT score as compared to others. These results showed a trend towards studies in which no significant difference was found between social classes and effect of diet on caries parevalence. ${ }^{21,5,17}$

In this study patients with poor oral hygiene had greater mean DMFT score of (1.99), followed very closely by average oral hygiene group (1.97). Good oral hygiene group had (1.74) score. These results were similar to those reported in other studies. ${ }^{30,31-32}$ Results showed a higher mean DMFT (1.98) in patients who did not have any dental care facilities as compared to other group in which the mean DMFT was (1.93). Results were statistically significant and showed an increase need of dental care facilities. Apart from that, it also showed lack of awareness and negligence on part of the patients for seeking dental treatment. 17,18,32

\section{CONCLUSIONS}

Within its limits, this research offers useful information on the prevalence of caries and related population risk factors. A significant role in the prevalence of dental caries was played by oral hygiene practices, dietary habits and access to dental care services. It was found that oral health was affected by socioeconomic status, parents' educational status and mass media, but without a major contribution. There is inadequate information on oral health-related diseases and methods of preventing them for people belonging to low SES. All these findings are consistent in showing high score of decayed and missing teeth as compared to filled. It suggests an imminent need of dental care facilities especially in under-privileged population.

Data sharing statement provided by the authors is available with the full text of this article at jemds.com.

Financial or other competing interests: None.

Disclosure forms provided by the authors are available with the full text of this article at jemds.com.

\section{REFERENCES}

[1] Dash JK, Sahoo PK, Bhuyan SK, et al. Prevalence of dental caries and treatment needs among children of Cuttack (Orissa). J Indian Soc Pedod Prev Dent 2002;20(4):13943.

[2] Sujatha B, Sankar AJS, Kumar MGM, et al. Prevalence of dental caries and treatment needs for the school going children of Guntur district, Andhra Pradesh. J Orofac Sci 2011;3(1):10-3.

[3] Blinkhorn AS, Hollloway PJ, Davies TG. Combined effect of flouride dentrifrices and mouth rinses on the incidence of dental caries. Community Dent Oral Epidemiol 1983;11(1):7-11.

[4] Burt BA, Eklund SA. Dentistry, dental practice and community. $5^{\text {th }}$ edn. United States of America: W.B Saunders Company 1999: p. 221-30.

[5] Coykendall AL, Specht PA, Samol HH. Streptococcus mutans in a wild, sucrose-eating rat population. Infect immune 1974;10(1):216-9.

[6] NIDR. National caries program: the prevalence of dental caries in United States children, 1986-87. NIH publication No. 89-2247, National Institute of Health 1989.

[7] Nikiforuk G. The changing pattern of oral disease: a global prospective. Artic Med Res 1988;47:545-53.

[8] Frencken J, Manji F, Mosha H. Dental caries prevalence amongst 12-year-old urban children in East Africa. Community Dent Oral Epidemiol 1986;14(2):94-8.

[9] Pilot T. The periodontal disease problem. A comparison between industrialised and developing countries. Int Dent J 1998;48(3 Suppl 1):221-32.

[10] World Health Organization. Oral health surveys: basic methods. 4th edn. Geneva: World Health Organization 1997.

[11] Papapanou PN. Epidemiology of periodontal diseases: an update. J Int Acad Periodontol 1999;1(4):110-6.

[12] Petersen PE. The World Oral Health Report 2003: continuous improvement of oral health in the $21^{\text {st }}$ century- the approach of the WHO Global Oral Health Programme. Community Dent Oral Epidemiol 2003;31(Suppl 1):3-24. 
[13] Pan American Health Organization. The health situation. In: Annual Report of the Director. Washington, DC: PAHO 1997.

[14] Schneider MC, Castillo-Salgado C, Bacallao J, et al. Methods for measuring health inequalities. WHO, Epidemiological Bulletin 2004;25:4-11.

[15] Maher R. Dental disorders in Pakistan--a national pathfinder study. J Pak Med Assoc 1991;41(10):250-2.

[16] Maher R, Khero R. Pilot oral health survey in balochistan. An overall review of dental disease in Pakistan: available data. J Pak Dent Assoc 1991;7(3-4):1987-95.

[17] Broderick EB, Niendorff WJ. Estimating dental treatment needs among American Indians and Alaska Natives. J Public Health Dent 2006;60(Suppl 1):250-5.

[18] Smith JM, Sheiham A. Dental treatment needs and demands of an elderly population in England. Community Dent Oral Epidemiol 1980;8(7):360-4.

[19] Cariono KMG, Shinada K, Kawaguchi Y. Childhood caries in northern philipines. Community Dent Oral Epidemiol 2003;31(2):81-9.

[20] Featherstone JD. Enhancement of remineralization invitro and in vivo. In: Leach SA, edr. Factors relating to demineralization and remineralization of the teeth. Oxford: IRL 1986

[21] Zero DT, Raubertas RF, Fu J, et al. Flouride concentration in plaque, whole saliva and duct saliva after application of home-use fluoride agents. J Dent Res 1992;71(11):176875.

[22] Van Loveren C, Duggal MS. The role of diet in caries prevention. Int Dent J 2001;51(6 Suppl 1):399-406.
[23] Haleem A, Khan AA. Dental caries and oral hygiene status of 12-year-old school children in Pakistan. Pak J Med Res 2001;40(4):138-42.

[24] Khan AA. Oral health in Pakistan: a situation analysis. Pakistan: Ministry of Health 2004.

[25] Kidd EA, Bechal SJ. Essentials of dental caries. $1^{\text {st }}$ edn. Dorchester: Hennery Ling Ltd., Dorset Press 1987:1-3.

[26] Albandar JM, Tinoco EMB. Global epidemiology of periodontal diseases in children and young persons. Periodontol 2002;29:153-76.

[27] Drury TF, Garcia I, Adesanya M. Socioeconomic disparities in adult oral health in the United States. Ann N Y Acad Sci 1999;896:322-4.

[28] Borrell LN, Burt BA, Neighbours HW, et al. Social factors and periodontitis in an older population. Am J Public Health 2004;94(5):748-54.

[29] Chen M, Andersen RM, Barmes DE, et al. Comparing oral health care systems. A Second International Collaborative Study. Geneva: World Health Organization 1997.

[30] Taani DQ. Relationship of socioeconomic background to oral hygiene, gingival status and dental caries in children. Quintessence Int 2002;33(3):195-8.

[31] Poster WJ, Pendrys DG, Morse DE, et al. Association of ethnicity/race and socioeconomic status with early childhood caries patterns. J Public Health Dent 2006;66(1):23-9.

[32] Van JP, Carvalho JC, D'Hoore W. Caries reduction in Belgian 12-year-old children related to socioeconomic status. Acta Odontol Scand 2002;60(2):123-8. 